\title{
Comparative Study for Microleakage in Three Retrograde Materials for Filling Root End-Biodentine, Mineral Trioxide Aggregate, and Portland Cement: An In Vitro Preliminary Study
}

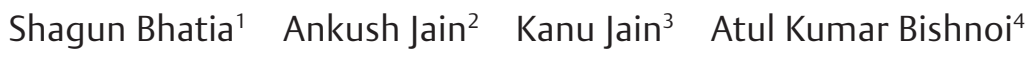 \\ ${ }^{1}$ Department of Conservative Dentistry and Endodontics, Luxmi Bai \\ Institute of Dental Sciences and Hospital, Patiala, Punjab, India \\ 2Periodontics and Oral Implantology, Private Practitioner, Patiala, \\ Punjab, India \\ ${ }^{3}$ Department of Oral and Maxillofacial Pathology, Maharaja Ganga \\ Singh Dental College and Research Centre, Sri Ganganagar, \\ Rajasthan, India \\ ${ }^{4}$ Department of Conservative Dentistry and Endodontics, Maharaja \\ Ganga Singh Dental College and Research Centre, Sri Ganganagar, \\ Rajasthan, India
}

\begin{abstract}
Address for correspondence Kanu Jain, MDS, Department of Oral and Maxillofacial Pathology, Maharaja Ganga Singh Dental College and Research Centre, Sri Ganganagar, Rajasthan 335002, India (e-mail: drkanupriyajain@gmail.com).
\end{abstract}

Dent J Adv Stud 2021;9:66-69.

\begin{abstract}
Keywords

- Biodentine

- microleakage

- mineral trioxide aggregate

- Portland cement

- retrograde filling material

Introduction Insufficient seal of apex is a significant reason for an endodontist's disappointment. The materials for root-end filling utilized ought to forestall departure of possible pollutants into periapical areas. The objective of this analysis was to compare the fixing capacity of three materials: white mineral trioxide aggregate (MTA), white Portland cement (PC), and Biodentine. This was analyzed through a test checking for dye leakage.

Materials and Methods Thirty human teeth having one root were subjected to instrumentation followed by gutta-percha obturation. An apical pit was readied for the material. The tooth samples were then grouped into three trial bunches: Group I, Biodentine; Group II, white MTA; and Group III, white PC. Root-end pits in the test bunches were loaded-up with the exploratory materials. The tooth samples were kept in India ink for a duration of 72 hours. The degree of color infiltration was estimated with the help of a stereomicroscope at $16 \times$ amplification. Color entrance was observed in the whole root in vitro.

Results The sequelae of this inspection found that Biodentine shows least leakage compared to MTA and PC.

Conclusion Biodentine shows less microleakage compared to MTA and PC.
\end{abstract}

\section{Introduction}

Certain materials are placed in root apices post canal treatment as intently as conceivable to accomplish a decent apical

DOI https://doi.org/ $10.1055 / \mathrm{s}-0041-1726671$ ISSN 2321-1482 seal. In addition, an efficient seal coronally as well as laterally is must for it to be successful. ${ }^{1}$ Forming a fluid tight seal is an assurance to ward off contaminants in this region through all channels, which is the ultimate goal of this instituted therapy. ${ }^{2}$
(C) 2021. Bhojia Dental College and Hospital affiliated to Himachal Pradesh University.

This is an open access article published by Thieme under the terms of the Creative Commons Attribution-NonDerivative-NonCommercial-License, permitting copying and reproduction so long as the original work is given appropriate credit. Contents may not be used for commercial purposes, or adapted, remixed, transformed or built upon. (https://creativecommons.org/licenses/by-nc-nd/4.0/).

Thieme Medical and Scientific Publishers Pvt. Ltd. A-12, 2nd Floor, Sector 2, Noida-201301 UP, India 
Furthermore, materials ought to be used in these situations ought to be biocompatible to tissues around root, nonresorbable, impenetrable to be dissolved, and possess good handling properties. $^{3}$ A great assortment of materials is available in history of dentistry that have been utilized for filling ends of roots. Some of them are transitional remedial material, cavit, super-EBA, amalgam, glass ionomer concrete (GIC), resin and carboxylate cement. ${ }^{4}$

Dye entrance is most regularly utilized strategy as these are inexpensive, modest, simple to be put away, and their infiltration is assessed quantitatively. Some of these to be put for this purpose are silver nitrate, basic fuchsine, India ink, silver nitrate, rhodamine $\mathrm{B}$, and blue methylene. To assess spillage, it is critical to choose a dye that is as little in size as could be expected under the circumstances, with the goal that it can go through the smallest of disparities at the tooth-rebuilding surface. Dye rhodamine B is favored as its subatomic size is moderately little, estimating just 1 nanometer. ${ }^{5}$

Mineral trioxide aggregate (MTA) is suggested for root-end filling seal and perforation repair and Biodentine is an additional material for recommendation. It is a bioactive dentin substitute and a biocompatible material with shorter setting time. The current analysis is intended for comparative study of sealing fixing capacity of Biodentine, MTA, and Portland cement (PC) and to discover which material is best as a radicular end material for filling.

\section{Materials and Methods}

Thirty extracted human single root teeth with developed apices, with no radicular caries, root break, or resorption were collected. These were the candidates that were taken out for weak periodontal issues and were later grouped as groups I, II, and III, each having 10 samples. Canal structure was affirmed preoperatively using radiographs. A size $10 \mathrm{~K}$-file (Dentsply Maillefer, Ballaigues, Switzerland) was brought into the canal following access cavity opening till its tip was obvious at the apex. Thereafter, $0.5 \mathrm{~mm}$ was subtracted to confirm the working length. This equivalent record was utilized as a patency document during readiness. The most extreme size of the underlying file was 20 that fitted at $\leq 1 \mathrm{~mm}$ from the peak. Roots in which introductory file size exceeded 20 were avoided from the investigation and supplanted with new roots. Step-back method was utilized for making canals until arriving at an ace apical record size of 40 . Then $2 \mathrm{~mL}$ of $3 \%$ sodium hypochlorite $(\mathrm{NaOCl})$ was flooded into the canals in between instrumentation. Finally, the canals were inundated with $5 \mathrm{~mL}$ of $3 \% \mathrm{NaOCl}$, trailed by water system with $5 \mathrm{~mL}$ of $17 \%$ ethylenediaminetetraacetic acid (EDTA; Pulpdent Corporation, MA, United States) and a last wash with $5 \mathrm{~mL}$ of $3 \% \mathrm{NaOCl}$. Obturation was done using gutta-percha and $\mathrm{AH}$ in addition as sealer (Dentsply Maillefer, Ballaigues, Switzerland) utilizing lateral compaction strategy. Overabundant gutta-percha was taken out with a warmth transporter and remaining was vertically consolidated at the canal openings using hand plugger. The nature of obturation was affirmed using radiographs, and GIC filling material was used to seal the canals. All specimens were put away for 7 days at $37 \pm 1^{\circ} \mathrm{C}$ and $100 \%$ relative humidity. With the help of a cross-cut fissure bur (556, Mani, Japan), apical $3 \mathrm{~mm}$ of the obturated roots was cut at apex at right angle to longitudinal plane. With the help of a straight fissure diamond bur (SF 41, Mani, Japan), a retrograde cavity of dimensions with depth $3 \mathrm{~mm}$ and width $0.8 \mathrm{~mm}$ wide was readied as per the canal morphology. EDTA followed by saline was then flooded into cavities and then they were left to dry. These prepared cavities were then loaded up with Biodentine, white MTA (ProRoot MTA; Dentsply, Tulsa, OK, United States), and white PC in groups I, II, and III, respectively, using Messing's transporter. All of these materials were used as per the instructions of the manufacturer. A ratio of 3:1 was used for mixing PC with distilled water. It was then filled with the help of amalgam carrier into the pit and completely condensed with the assistance of finger plugger.

Afterward, all roots were enclosed by a wet bandage and put in incubator for 48 hours at $37^{\circ} \mathrm{C}$ to permit total arrangement of all the filling materials. Three layers of varnish were then placed one by one in all the categories, leaving $1 \mathrm{~mm}$ of apical end of cut root, and were then permitted to dry. All the apices were then kept in Indian ink at $37^{\circ} \mathrm{C}$ and $100 \%$ relative humidity for 72 hours. From that point, the roots were taken out, washed for 15 minutes under running tap water, and then were dried in air. Diamond disks were used to segment the blocks into two equal parts vertically in a buccolingual direction under extensive cold water irrigation.

The degree of infiltration into root canal at apex was estimated utilizing stereomicroscope (NSZT-44E Radical Instruments; 20× amplification) and was recorded in micrometers for all the three categories (-Figs. 1-3). All the pictures

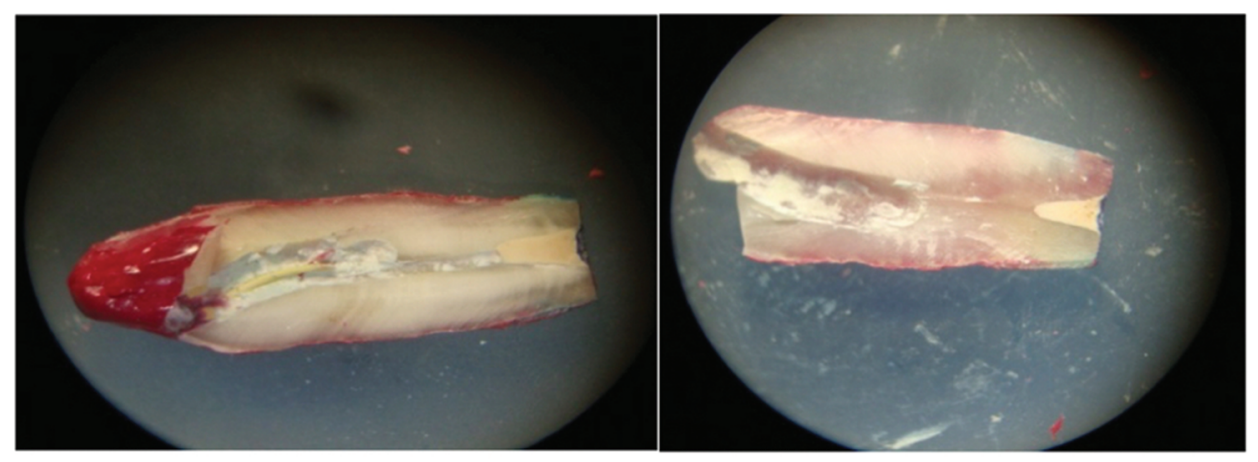

Fig. 1 Image of dye penetration with Biodentine (Group I). 


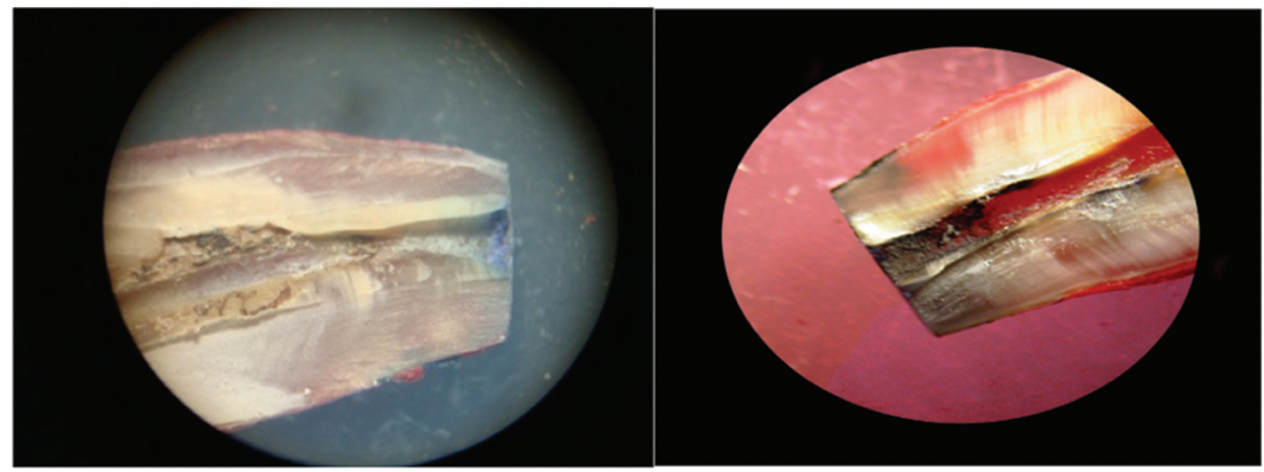

Fig. 2 Image of dye penetration with mineral trioxide aggregate (Group II).
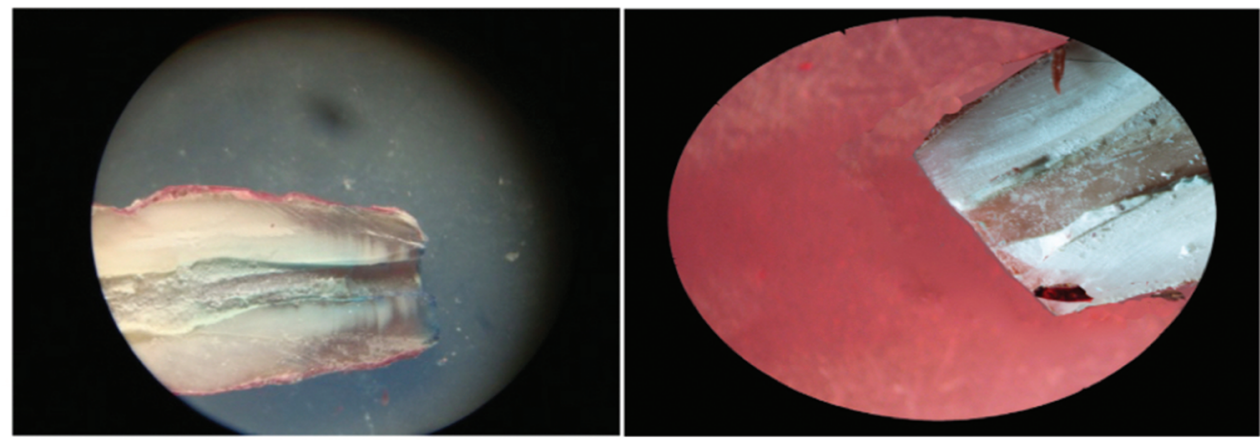

Fig. 3 Image of dye penetration with Portland cement (Group III).

Table 1 Microleakage values in three different groups

\begin{tabular}{|l|l|l|l|l|l|l|}
\hline Groups & $\boldsymbol{n}$ & Mean & SD & $p^{*}$ & $p^{\S}$ & $p^{\dagger}$ \\
\hline Group I: Biodentine & 30 & 0.47 & 0.62 & - & 0.003 & 0.004 \\
\hline Group II: MTA & 30 & 1.19 & 0.74 & 0.003 & - & 0.727 \\
\hline Group III: PC & 30 & 1.43 & 0.75 & 0.004 & 0.727 & - \\
\hline
\end{tabular}

Abbreviations: MTA, mineral trioxide aggregate; PC, Portland cement; SD, standard deviation.

$p^{*}$ : comparison with Biodentine.

$p^{\S}$ : comparison with MTA.

$p^{\dagger}$ : comparison with PC.

captured utilizing a Canon DSLR computerized camera were then fed into Adobe Photoshop CS2 (Adobe Corporation, United States). To gauge the profoundness of dye entrance along the interface of the root-end filling, the metallic ruler was utilized. Results along these lines were compared and put under statistical examination. Computation of mean and standard deviation (SD) was followed by Tukey's test and one-way analysis of variance (ANOVA).

\section{Results}

Mean \pm SD represented the quantitative values of the analysis. To calculate and compare the difference between different categories, independent $t$-test and ANOVA and post hoc Tukey test were utilized. Examination of the level of spillage shows measurably huge contrast between three groups ( $p=$ 0.04). A factually critical distinction was observed between groups I and II and groups I and III (-Table 1), while no measurable difference was observed between groups II and III.
Post hoc Tukey test was utilized for individual correlation of gatherings.

\section{Discussion}

The current examination analyzed the fixing capacity of three filling materials for resected root ends (Biodentine, PC, and MTA). The observations of the current investigation exhibit that Biodentine shows a huge contrast with MTA and PC in terms of fixing capacities of these substances. Different concretes have been utilized as filling materials in the past. The decision of a root-end filling material could be administered by dealing with properties, degree of apical seal, biocompatibility, and clinical achievement in the long term. MTA has been researched and utilized as a root-end filling material since its presentation. Notwithstanding its great physical and organic properties and it being hydrophilic in nature, its utilization has consistently stayed a test as a result of its strategy affectability, drawn-out setting time, and significant 
expense. There has been a quest for an elective material with the intention to decrease cost and increase the achievability for both experts and patients.

Biodentine is like MTA in its fundamental creation. The powder essentially contains tricalcium silicate, and dicalcium silicate and calcium carbonate-the important segments of MTA. Zirconium oxide fills in as the radiopacifier. The fluid comprises of calcium chloride in watery arrangement with polycarboxylate. The expansion of calcium chloride, setting quickening agent, brings about quick setting as well as improves its properties and quality. Setting time of calcium silicate has a great range. Diminishing the setting time was accomplished by a blend of various impacts. First, molecule size extraordinarily impacts the setting time. Additionally, calcium chloride addition to the fluid segment quickens the framework. At last, the lessening of the fluid substance in the framework diminishes the setting time to solidify within 9 to 12 minutes. ${ }^{6}$ Kokate and Pawar conducted an examination that looked at the microleakage of MTA, GIC, and Biodentine when utilized as retrograde filling material. They reasoned that microleakage was least displayed by Biodentine when contrasted with other materials. ${ }^{7}$ This analysis showed that high $\mathrm{pH}$ along with constant influx of calcium ions are important requisites in hard tissue mineralization process of healing.

In another study by Sulthan et al, it was observed that the ability of Biodentine ${ }^{\mathrm{TM}}$ to present alkaline $\mathrm{pH}$ and calcium particle release is quite same as that of MTA. ${ }^{8}$ However, uptake of Biodentine in its elemental form into dentin was observed to be significantly more as compared with MTA in another research by Han and Okiji. ${ }^{9}$ Since the acquaintance of Biodentine, the decision to use it as a material for filling at root ends so far is not so concrete as there is exceptionally less research on it so far. A few investigations have shown that MTA displays essentially lesser spillage than different materials. Although the properties and impacts of PC and MTA are nearly similar, the only reason for PC as material of choice goes for it being an inexpensive alternative.

The observations from the current examination were likewise upheld by Islam et al, who analyzed the in vitro fixing capacity of materials for root-end fill substances-white MTA, gray MTA, conventional PC, and white PC. ${ }^{10}$ They concluded that none of the teeth indicated spillage past filling materials. Similarly, no significant differences were observed by De-Deus et al while they performed critical contrasts between the fixing capacity of PC and MTA for their ability to repair furcation. ${ }^{11}$

\section{Conclusion}

The consequences of the current examination uncovered that Biodentine shows least microleakage as compared to MTA and PC. So Biodentine is one of the biocompatible retrograde filling substances with lesser setting time and low cost. The inexpensive nature and clearly comparative fixing capacity of PC to MTA, makes it a potential replacement for MTA. This can be considered in spite of the fact that the lower radiopacity of PC is its significant weakness in the event that it is to be utilized clinically.

\section{Conflict of Interest}

None declared.

\section{References}

1 Adel M, Nima MM, Shivaie Kojoori S, Norooz Oliaie $H$, Naghavi N, Asgary S. Comparison of endodontic biomaterials as apical barriers in simulated open apices. ISRN Dent 2012;2012:359873

2 Bortoluzzi EA, Broon NJ, Bramante CM. Garcia RB, de Moraes IG, Bernardineli N. Sealing ability of MTA and radiopaque Portland cement with or without calcium chloride for root-end filling. J Endod 2006;32(9):897-900

3 Maltezos C, Glickman GN, Ezzo P, He J. Comparison of the sealing of Resilon, Pro Root MTA, and Super-EBA as root-end filling materials: a bacterial leakage study. J Endod 2006; 32(4):324-327

4 Vogt BF, Xavier CB, Demarco FF, Padilha MS. Dentin penetrability evaluation of three different dyes in root-end cavities filled with mineral trioxide aggregate (MTA). Braz Oral Res 2006;20(2):132-136

5 El Sayed M, Saeed M. In vitro comparative study of sealing ability of Diadent BioAggregate and other root-end filling materials. J Conserv Dent 2012;15(3):249-252

6 SeptodontBiodentine ${ }^{\mathrm{TM}}$ Active BiosilicateTechnology TM scientific file, 2010

7 Kokate SR, Pawar AM. Anin vitrocomparative stereomicroscopic evaluation of marginal seal between MTA, glass inomer cement \& biodentine as root end filling materials using $1 \%$ methylene blue as tracer. Endod 2012;2:36-42

8 Sulthan IR, Ramchandran A, Deepalakshmi A, Kumarapan SK. Evaluation of $\mathrm{pH}$ and calcium ion release of mineral trioxide aggregate and a new root-end filling material. J Dent 2012; 2:166-169

9 Han L, Okiji T. Uptake of calcium and silicon released from calcium silicate-based endodontic materials into root canal dentine. Int Endod J 2011;44(12):1081-1087

10 Islam I, Chng HK, Yap AU. Comparison of the root-end sealing ability of MTA and Portland cement. Aust Endod J 2005;31(2):59-62

11 De-Deus G, Petruccelli V, Gurgel-Filho E, Coutinho-Filho T. MTA versus Portland cement as repair material for furcal perforations: a laboratory study using a polymicrobial leakage model. Int Endod J 2006;39(4):293-298 